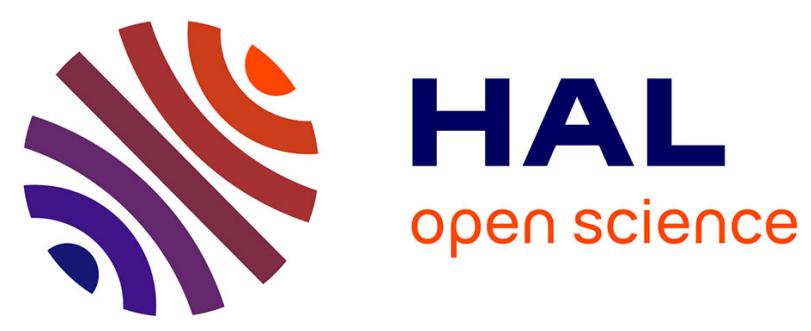

\title{
Small hyaluronan oligosaccharides induce inflammation by engaging both toll-like- 4 and cd44 receptors in human chondrocytes
}

Giuseppe M. Campo, Angela Avenoso, Salvatore Campo, Angela d'Ascola, Giancarlo Nastasi, Alberto Calatroni

\section{To cite this version:}

Giuseppe M. Campo, Angela Avenoso, Salvatore Campo, Angela d'Ascola, Giancarlo Nastasi, et al.. Small hyaluronan oligosaccharides induce inflammation by engaging both toll-like- 4 and cd 44 receptors in human chondrocytes. Biochemical Pharmacology, 2010, 80 (4), pp.480. 10.1016/j.bcp.2010.04.024 . hal-00601166

\section{HAL Id: hal-00601166 https://hal.science/hal-00601166}

Submitted on 17 Jun 2011

HAL is a multi-disciplinary open access archive for the deposit and dissemination of scientific research documents, whether they are published or not. The documents may come from teaching and research institutions in France or abroad, or from public or private research centers.
L'archive ouverte pluridisciplinaire HAL, est destinée au dépôt et à la diffusion de documents scientifiques de niveau recherche, publiés ou non, émanant des établissements d'enseignement et de recherche français ou étrangers, des laboratoires publics ou privés. 


\section{Accepted Manuscript}

Title: Small hyaluronan oligosaccharides induce inflammation by engaging both toll-like- 4 and cd44 receptors in human chondrocytes

Authors: Giuseppe M. Campo, Angela Avenoso, Salvatore Campo, Angela D'Ascola, Giancarlo Nastasi, Alberto

Calatroni

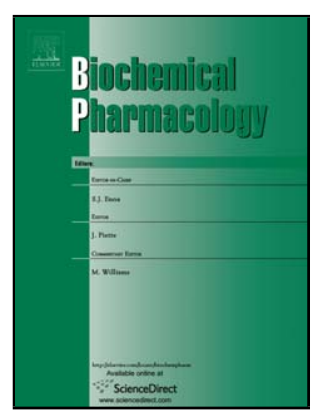

PII:

DOI:

Reference:

S0006-2952(10)00298-4

doi:10.1016/j.bcp.2010.04.024

BCP 10541

To appear in: $\quad B C P$

Received date: $\quad 8-2-2010$

Revised date: $\quad 17-4-2010$

Accepted date: $\quad$ 20-4-2010

Please cite this article as: Campo GM, Avenoso A, Campo S, D'Ascola A, Nastasi G, Calatroni A, Small hyaluronan oligosaccharides induce inflammation by engaging both toll-like-4 and cd44 receptors in human chondrocytes, Biochemical Pharmacology (2008), doi:10.1016/j.bcp.2010.04.024

This is a PDF file of an unedited manuscript that has been accepted for publication. As a service to our customers we are providing this early version of the manuscript. The manuscript will undergo copyediting, typesetting, and review of the resulting proof before it is published in its final form. Please note that during the production process errors may be discovered which could affect the content, and all legal disclaimers that apply to the journal pertain. 
SMALL HYALURONAN OLIGOSACCHARIDES INDUCE INFLAMMATION BY ENGAGING BOTH TOLL-LIKE-4 AND CD44 RECEPTORS IN HUMAN CHONDROCYTES

Giuseppe M. Campo, Angela Avenoso, Salvatore Campo, Angela D’Ascola, Giancarlo Nastasi, Alberto Calatroni.

Department of Biochemical, Physiological and Nutritional Sciences, Medicinal Chemistry section, School of Medicine, University of Messina, Policlinico Universitario, 98125 - Messina, Italy

Running title: TLR-4 modulation by GAGs in LPS-stimulated chondrocytes

Correspondence to: Giuseppe M. Campo, PhD, Department of Biochemical, Physiological and Nutritional Sciences, School of Medicine, University of Messina, Policlinico Universitario, Torre Biologica, 5 piano, Via C. Valeria - 98125 - Messina, Italy; phone +39 090221 3334; fax +39 090221 3330; e-mail gcampo@unime.it 


\section{ABSTRACT}

Small degradation fragments of hyaluronan (HA) may stimulate an inflammatory response in a variety of tissues at the injury site. HA oligosaccharides are endogenous ligands for the CD44 receptor as well as for toll-like receptor 4 (TLR-4). Previous data have shown that HA fragments may induce pro-inflammatory cytokine expression by interacting with both the CD44 receptor and TLR-4. CD44 and TLR-4 stimulation activates different inflammatory pathways that culminate with the activation of the transcriptional nuclear factor kappaB (NF-kB) which is responsible for the expression of inflammation mediators such as tumor necrosis factor alpha (TNF- $\alpha$ ), interleukin-6 (IL-6) and interleukin-1 beta (IL-1 $\beta$ ). The aim of this study was to investigate the inflammatory effects of very small HA oligosaccharides on both TLR-4 and CD44 involvement in normal human articular chondrocytes.

Adding HA fragments to chondrocyte cultures up-regulated CD44 and TLR-4 expression, activated NF-kB translocation and increased the pro-inflammatory cytokines TNF- $\alpha$, IL-6 and IL-1 $\beta$.

The addition of a specific CD44 blocking antibody reduced CD44 and all inflammatory cytokine expression as well as protein production. However, cytokine expression remained significantly higher than in untreated chondrocytes. TLR-4 expression was not affected. The treatment with TLR-4 blocking antibody decreased TLR-4 and inflammatory cytokine expression, although cytokine expression was significantly higher than in control cells. CD44 expression was unaffected. The addition of both CD44 and TLR-4 blocking antibodies significantly reduced CD44, TLR-4 and inflammatory cytokine expression.

Key words: Hyaluronan, cytokines, chondrocytes, NF-kB , TLR-4 


\section{Introduction}

Toll-like receptors are a class of proteins that play a key role in the innate immune system. They recognize structurally conserved molecules derived from microbes. Once these microbes cross physical barriers such as the skin or intestinal tract mucosa, they are recognized by TLRs which activates the innate immune response [1]. Although each TLR recognizes specific ligands, they may trigger other different molecules. Recently, the glycosaminoglycan (GAG) hyaluronan (HA) has also been identified as an inducer of TLR-4 activation, capable of causing the release of proinflammatory cytokines [2-3].

ECM is a complex mixture of proteins, glycoproteins, proteoglycans (PGs) and GAGs. ECM plays several biological roles, in particular mechanical strength and also provides signals affecting cell adhesion, shape, migration, proliferation, survival and differentiation [4-5]. ECM presents many domains that become active after proteolytic or glycolytic cleavage. These active ECM fragments are called matrikines and they may play different roles, in particular they may act as potent inflammatory mediators including collagen type one and four, elastin, fibronectin, laminins, entactin/nidogen, thrombospondin, HA [5]. Among these, HA is the most widely studied because of its varying activity depending on the different state of aggregation. HA may exist both as a soluble polymer as well as in complexes with non-covalently linked proteins called HA-binding proteins or hyaladherins. HA exists as a high-molecular-weight polymer $\left(10^{6} \mathrm{D}\right)$ under physiological conditions. However, under inflammatory conditions HA has been shown to have greater polydispersity in size, with a preponderance of low molecular weight forms, especially after tissue injury [6]. HA functions are determined in part by the size of the molecule, in addition to the structure and its interaction with HA binding proteins.

The cluster determinant 44 (CD44) is the best-known receptor of HA [7]. CD44 is a transmembrane glycoprotein that is widely distributed on leukocytes and several other cell types. CD44 stimulation with HA plays a role in various physiological functions, e.g. cell adhesion, cellsubstrate interaction, and lymphocyte recruitment, as well as in pathological processes such as 
inflammation and metastasis [8]. Previous studies have reported that the separate stimulation of TLR4 and CD44 receptors may prime pro-inflammatory intermediates through NF-kB activation [ 9-10].

It has also been reported that fragments of HA or HA at low molecular weight are able to interact with TLR-4 and CD44 receptors, thereby stimulating inflammation or increasing the inflammatory mechanism previously induced by other agents in different cell types [11-16]. Hence, the generation of lower molecular weight HA in pathologies may act as an endogenous danger signal, leading to the activation of both innate and acquired immunity.

As, in two separated experiments, we previously reported that low molecular weight HA (50 kD) significantly activated NF-kB-induced transcription of pro-inflammatory mediators [15-16] by stimulating TLR-4 or CD44 receptors, the aim of the present study was to evaluate whether the inflammation stimulated by low molecular weight HA or other small HA fragments could be the result of the activation of both TLR-4 and CD44 receptors. For this purpose we treated normal human chondrocytes with a specific HA oligosaccharide containing only six monosaccharides (6mer) since previous reports [17-18] had shown that HA at this size was able to stimulate inflammation by interacting with both receptors TLR-4 and CD44. We also evaluated the degree of inflammation by using specific selective blocking antibodies.

\section{Materials and methods}

\subsection{Materials}

HA 6-mer oligosaccharides as sodium salt were obtained from Cosmo Bio Co., Ltd (Tokyo, Japan). The product was endotoxin free (endotoxin content $<0.1 \mathrm{ng} / \mathrm{mg}$ ). Antibodies against the TLR-4 receptor to evaluate TLR-4 protein levels and to block its activity were supplied by Santa Cruz Biotechnology (Santa Cruz, CA, USA). Antibodies against NF-kB p50/p65 subunits and antibodies against the CD44 receptor to evaluate CD44 protein levels and to block its activity were supplied by Cell Signalling Technology (Danvers, MA, USA). Human TNF- $\alpha$ (cat. DTA00C), IL-6 (cat. 
PD6050), and IL-1 $\beta$ (cat. DLB50) commercial ELISA kits were provided by R\&D Systems Inc. (Minneapolis, MN, USA). Dulbecco’s modified Eagle’s medium (DMEM), foetal bovine serum (FBS), L-glutamine, penicillin/streptomycin, trypsin-EDTA solution and phosphate buffered saline (PBS) were obtained from Gibco Brl (Grand Island, NY, USA). All cell culture plastics were obtained from Falcon (Oxnard, CA, USA). RNase, proteinase K, protease inhibitor cocktail, sodium dodecylsulphate (SDS) and all other general laboratory chemicals were obtained from SigmaAldrich S.r.l. (Milan, Italy).

\subsection{Cell Cultures}

Primary human chondrocytes from articular cartilage (cod. 06090702), provided by ECACC-Health Protection Agency -Cell Applications (Salisbury, UK), were cultured in $75 \mathrm{~cm}^{2}$ plastic flasks containing $15 \mathrm{ml}$ of DMEM to which 10\% FBS, L-glutamine (2.0 mM) and penicillin/streptomycin (100 U/ml, $100 \mu \mathrm{g} / \mathrm{ml}$ ) were added and then incubated at 37 $\mathrm{C}$ in humidified air with 5\% CO2. Experiments were performed using chondrocyte cultures between the third and the fifth passage.

\subsection{HA treatment}

Chondrocytes were cultured in six-well culture plates at a density of $1.3 \times 10^{5}$ cells/well. Twelve hours after plating (time 0) 6-mer HA was added using three different doses of 10, 20 and $40 \mu \mathrm{g} / \mathrm{ml}$. A separate set of plates were also first treated with the specific antibody against either TLR-4 or CD44 receptors alone or with both antibodies, or/and NF-kB p50/p65 subunits and HA was added 60 minutes after the antibody treatment. Finally, the cells and medium underwent biochemical evaluation 24 hours later. Being for experimental use, 6-mer HA was diluted to a final concentration of $10-40 \mu \mathrm{g} / \mathrm{ml}$, the maximum estimated endotoxin content of $0.004 \mathrm{ng} / \mathrm{ml}$ for a 40 $\mu \mathrm{g} / \mathrm{ml}$ concentration. The study therefore included the following groups of cells: a first set of five groups (control, HA vehicle, HA $10 \mu \mathrm{g} / \mathrm{ml}$, HA $20 \mu \mathrm{g} / \mathrm{ml}$ and HA $40 \mu \mathrm{g} / \mathrm{ml}$ ) untreated with any 
anti-TLR-4 or CD44 antibodies; a second set of the same five groups treated 60 minutes before HA addition with a specific antibody against the CD44 receptor; a third set of the same five groups again treated 60 minutes before HA addition with a specific antibody, this one against the TLR-4 receptor, a final set of the same five groups treated 60 minutes before HA addition with a specific antibodies against both the TLR-4 and CD44 receptors. The mRNA expression and the related protein production of TLR-4, CD44, TNF- $\alpha$, IL-6 and IL-1 $\beta$ were evaluated for each set of these five groups.

\subsection{RNA isolation, cDNA synthesis and real-time quantitative PCR amplification}

Total RNA was isolated from chondrocytes for reverse-PCR real time analysis of TLR-4, CD44, TNF- $\alpha$, IL-6 and IL-1 $\beta$ (RealTime PCR system, Mod. 7500, Applied Biosystems, USA) using an Omnizol Reagent Kit (Euroclone, West York, UK). The first strand of cDNA was synthesized from $1.0 \mu \mathrm{g}$ total RNA using a high capacity cDNA Archive kit (Applied Biosystems, USA). $\beta$-actin mRNA was used as an endogenous control to allow the relative quantification of TLR-4, CD44, TNF- $\alpha$, IL-6 and IL-1 $\beta$. PCR RealTime was performed by means of ready-to-use assays (Assays on demand, Applied Biosystems) on both targets and endogenous controls. The amplified PCR products were quantified by measuring the calculated cycle thresholds $\left(\mathrm{C}_{\mathrm{T}}\right)$ of TLR-4, CD44, TNF$\alpha$, IL-6, IL-1 $\beta$, and $\beta$-Actin mRNA. The $\mathrm{C}_{\mathrm{T}}$ values were plotted against the log input RNA concentration in serially diluted total RNA of chondrocyte samples and used to generate standard curves for all mRNAs analysed. The amounts of specific mRNA in samples were calculated from the standard curve and normalized with $\beta$-actin mRNA. After normalization, the mean value of normal cartilage cell target levels became the calibrator (one per sample) and the results are expressed as the $n$-fold difference relative to normal controls (relative expression levels). 


\subsection{Western blot assay of TLR-4 and CD44 proteins}

For SDS-PAGE and Western blotting, chondrocytes were washed twice in ice-cold PBS and subsequently dissolved in SDS sample buffer (62.5 mм Tris/HCl, $\mathrm{pH} 6.8,2 \% \mathrm{w} / \mathrm{v}$ SDS, 10\% glycerol, $50 \mathrm{mM}$ dithiothreitol, $0.01 \% \mathrm{w} / \mathrm{v}$ bromophenol blue). $\beta$-actin protein was used as an endogenous control to allow the normalization of TLR-4 and CD44 proteins. Aliquots of the protein extracted (10-25 $\mu \mathrm{l} /$ well) were separated on a mini gel (10\%). The proteins were blotted onto polyvinylidene difluoride membranes (Amersham Biosciences) using a semi-dry apparatus (BioRad). The blots were flushed with double distilled $\mathrm{H}_{2} \mathrm{O}$, dipped into methanol, and dried for 20 min before proceeding on to the next steps. Subsequently, the blots were transferred to a blocking buffer solution (1x PBS, $0.1 \%$ Tween 20, 5\% w/v non-fat dried milk) and incubated for $1 \mathrm{~h}$. The membranes were then incubated with the specific diluted (1:1) primary antibody in 5\% bovine serum albumin, $1 \mathrm{x}$ PBS, and $0.1 \%$ Tween 20 and stored in a roller bottle at $4{ }^{\circ} \mathrm{C}$ overnight After being washed in three stages in wash buffer (1x PBS, 0.1\% Tween 20), the blots were incubated with the diluted $(1: 5,000)$ secondary polyclonal antibody (goat anti-rabbit conjugated with peroxidase, Santa Cruz Biotechnology, Santa Cruz, CA, USA) in TBS/Tween-20 buffer containing 5\% non-fat dried milk. After 45 min of gentle shaking, the blots were washed five times in wash buffer and the proteins were made visible using a UV/visible transilluminator (EuroClone, Milan, Italy) and Kodak BioMax MR films. A densitometric analysis was also run in order to quantify each band.

\subsection{NF-kB p50/65 transcription factor assay}

NF-kB p50/65 DNA binding activity in nuclear extracts of chondrocytes was evaluated in order to measure the degree of NF-kB activation. The analysis was carried out following the manufacturer's protocol for a commercial kit (NF-kB p50/65 Transcription Factor Assay Colorimetric, cat. nSGT510, Chemicon International, USA). In brief, cytosolic and nuclear extraction was performed by lysing the cell membrane with an apposite hypotonic lysis buffer containing protease inhibitor 
cocktail and tributylphosphine (TBP) as reducing agent. After centrifugation at 8,000 x g, the supernatant containing the cytosolic fraction was stored at $-80^{\circ} \mathrm{C}$, while the pellet containing the nuclear portion was then re-suspended in the apposite extraction buffer and the nuclei were disrupted by a series of drawing and ejecting actions. The nuclei suspension was then centrifuged at $16,000 \mathrm{x} \mathrm{g}$. The supernatant fraction was the nuclear extract. After determining protein concentration and adjustment to a final concentration of approximately $4.0 \mathrm{mg} / \mathrm{ml}$, this extract was stored in aliquots at $-80^{\circ} \mathrm{C}$ for the subsequent NF-kB assay. After incubation with primary and secondary antibodies, colour development was observed following the addition of the substrate TMB/E. Lastly, the absorbance of the samples was measured using a spectrophotometric microplate reader set at $\lambda 450 \mathrm{~nm}$. Values are expressed as relative optical density (OD) per mg protein.

\subsection{TNF- $\alpha$, IL-6 and IL-1 $\beta$ ELISA assay}

Samples of cell-secreted protein extracted from the culture media in the presence of $1 \mathrm{nM}$ PMSF and protease inhibitor cocktail were centrifuged at $13,000 \mathrm{rpm}$ at $4^{\circ} \mathrm{C}$ for $10 \mathrm{~min}$,. The analysis of TNF- $\alpha$, IL-6 and IL-1 $\beta$ was carried out using a specific commercial kit. Briefly, $100 \mu$ of assay diluent was added to each well of the coated microplate followed by the addition of $100 \mu$ l of standards, samples and controls to each well. After two hours of incubation at room temperature, the supernatant of each well was aspirated and the plate was washed four times. Wells were filled with $200 \mu \mathrm{l}$ of each specific biotin-conjugate antibody. After two hours of incubation at room temperature, the liquid from the wells was discarded and the plate washed four times to which 200 $\mu \mathrm{l}$ of substrate solution was then added. After further incubation for 20 min (protected from light) $50 \mu \mathrm{l}$ of a stop solution was added. The absorbance of each well was read spectrophotometrically, within 30 minutes, at $\lambda 450 \mathrm{~nm}$. TNF- $\alpha$, IL-6 and IL-1 $\beta$ values are expressed as $\mathrm{pg} / \mathrm{ml}$. 


\subsection{Protein determination.}

The amount of protein was determined using the Bio-Rad protein assay system (Bio-Rad Lab., Richmond, CA, USA) with bovine serum albumin as a standard, in accordance with the published method [19].

\subsection{Statistical analysis}

Data are expressed as the mean \pm S.D. values of at least seven experiments for each test. All assays were repeated three times to ensure reproducibility. Statistical analysis was performed by one-way analysis of variance (ANOVA) followed by the Student-Newman-Keuls test. The statistical significance of differences was set at $\mathrm{p}<0.05$.

\section{Results}

\subsection{TLR-4 and CD44 mRNA expression and Western blot analysis.}

TLR-4 and CD44 mRNA evaluation (Figs 1 and 2, panels A, B, C and D of each Figure) and Western blot analysis with densitometric evaluation (Figs. 1 and 2, panels E, F, G and H of each Figure) were assayed in order to estimate the degree of TLR-4 and CD44 activation in the presence/absence of 6-mer HA with/without the specific antibodies against TLR-4 (panel C), CD44 (panel B) or against both receptors (panel D). The results showed a marked dose-dependent increase in the expression and protein synthesis of the TLR-4 receptor (Fig.1) in chondrocytes treated with 6-mer HA and those untreated with any TLR-4 and CD44 antibodies. The same results were also obtained in chondrocytes pre-treated with the antibody against the CD44 receptor. These results mean that 6-mer HA, by interacting with TLR-4, was able to increase TLR-4 expression and protein synthesis and the CD44 blocking antibody did not interfere with the activation. However, pretreatment of chondrocytes with the specific antibody against the TLR-4 produced no effect in cells exposed to 6-mer HA. This finding means that TLR-4 was the target for 6-mer HA and the pretreatment with the specific anti-TLR-4 antibody prevented TLR-4-HA interaction. Similar results 
were obtained by pre-treating chondrocytes with both anti-TLR-4 and anti CD44 antibodies. Analogous results were seen on evaluating CD44 mRNA expression and the related protein levels (Fig.2). In this case 6-mer HA was also able to interact with the CD44 receptor, increasing its expression and protein levels in a dose-dependent manner. These results confirm that the CD44 receptor also functions as target for 6-mer HA Blocking this receptor prevented CD44-HA interaction and the increase of its expression. Once again, the pre-treatment of chondrocytes with the antibody against the TLR-4 receptors did not interfere with CD44-HA interaction (Figs. 1 and 2). No effects were observed in 6-mer HA un-stimulated cells, as well as no changes were seen in 6mer stimulated chondrocytes and pre-treated with the NF-kB antibodies (data not shown).

\subsection{NF-kB activation.}

Fig. 3 shows the changes in the NF-kB p50/p65 heterodimer translocation over the course of the experiment, in the absence (panel A) and the presence (panels B, C and D) of antibodies. This assay was also carried out in order to estimate the initiation of inflammatory process, since the NF-kB factor can be activated by both the TLR and CD44 pathways that in turn may converge to stimulate the expression of several genes that prime/amplify inflammation. The results obtained by evaluating the NF-kB factor confirmed that 6-mer HA was able to activate NF-kB expression in a significant dose-dependent manner via both TLR-4 and CD44 receptors. Interestingly, the chondrocytes pretreated with the specific antibody against CD44 (panel B) showed a significant reduction in NF-kB activation, although activation remained significant and dose-dependent. A similar result was obtained by pre-treating chondrocytes with the specific antibody against the TLR-4 receptor (panel C). Pre-blocking both TLR4 and CD44 receptors drastically reduced NF-kB activation induced by 6-mer HA (panel D). while NF-kB activation was not completely suppressed by this pre-blocking of the two receptors, thus demonstrating that 6-mer HA may also activate NF-kB through the stimulation of other pathways that differ from TLR-4 and CD44 receptors. No significant effect was 
seen in 6-mer HA un-stimulated cells and in 6-mer HA stimulated cells previous treated with the specific NF-kB antibodies and TLR-4/CD44 antibodies.

\subsection{Pro-inflammatory cytokines mRNA expression and protein levels.}

TNF- $\alpha$ (Fig. 4), IL-6 (Fig. 5) and IL-1 $\beta$ (Fig. 6) mRNA evaluation (panels A, B, C, and D of each Figure), and ELISA assay (panels E, F, G and $\mathrm{H}$ of each Figure) confirmed the previous data obtained by evaluating the NF-kB factor. In fact, the results showed a marked dose-dependent increase in the expression and protein synthesis of all inflammatory cytokines in chondrocytes treated with 6-mer HA but not treated with any anti-TLR-4 and anti-CD44 antibodies (panels A and E). This increase is a direct consequence of NF-kB activation by 6-mer HA-induced stimulation of TLR-4 and CD44 receptors. The pre-treatment of chondrocytes with the specific antibody against TLR-4 (panels C and G) or the specific antibody against CD44 (panels B and F) was able to significantly decrease these inflammatory cytokines as a consequence of the reduction in NF-kB activation. The pre-treatment of cells with both blocking antibodies (panels D and H) produced a further significant decrease in these inflammatory mediators although, once more, their expression was not completely suppressed, therefore suggesting other possible targets for 6-mer HA or activation of other pathways not mediated by NF-kB. The block of NF-kB translocation in chondrocytes stimulated with 6-mer HA produced a slight significant effect on the production of all pro-inflammatory cytokines. This effect was significant for TNF- $\alpha$ levels both in cells untreated with TLR-4 and CD44 antibodies and cells treated with TLR-4 antibodies. It was not effective in chondrocytes treated with CD44 and CD44 plus TLR-4 antibodies. The same trend was observed for IL-6 and IL-1 $\beta$ levels, except the fact that in this case the increment in the cytokine expression and protein production was at limit of significance. This pro-inflammatory cytokine activation, not mediated by NF-kB, but mediated by CD44 receptor could be the result of PKC activation due to 6mer HA-induced CD44 stimulation that may directly activate TNF- $\alpha$ which in turn may activate other pro-inflammatory cytokines such as IL-6 and IL-1 $\beta$. These results taken together could mean 
that small fragments of HA prime inflammation in part by interacting with both TLR-4 and CD44 receptors, since the partial block or the total block of these receptors may change the production of the inflammation mediators TNF- $\alpha$, IL-6 and IL-1 $\beta$.

\subsection{Hypothetical mechanism from the reformulation of the results}

The data of the present study concur with results previously obtained [15-16] and allow us to hypothesize the following integrated mechanism (Scheme 1). In normal conditions, native HA is produced on the inner surface of the plasma membrane and extruded into the extracellular environment. It binds TLR-4 and CD44 receptors and it is able to maintain the homeostasis of the cell. CD44 deals with normal HA degradation in small fragments and internalization and the successive passage first to endosomes and then to lysosomes where hyaluronidases, especially hyaluronidase-1 (HYAL-1), look after its further degradation (panel A). Following inflammatory stimuli, generated by different pathologies, such as arthritis, diabetes, cirrhosis, etc., native HA is massively degraded by reactive oxygen species and hydrolytic enzymes, such as hyaluronidases, chondroitinases and exosaminidases, whose expression increase dramatically during tissue injury, into small fragments, which are able to stimulate TLR-4 and CD44 receptors (panel B). The TLR-4 and CD44 stimulation exerted by these HA fragments, in turn primes inflammation by two different pathways that finally both converge in NF-kB activation. Activated NF-kB moves to the nucleus where it primes the transcription of several pro-inflammatory mediators, such as TNF- $\alpha$, IL- $1 \beta$ and IL-6. Pro-inflammatory mediators, in turn, are responsible for HA synthase induction, particularly HA synthase-3, that leads to increased HA production, at not very high molecular weight, which is in part deposited in tissues and in part degraded via the mechanism illustrated above. The further degradation of the newly produced HA continues to stimulate TLR-4 and CD44 receptors and therefore the outcome is the amplification and the perpetuation of inflammation (panel C). High molecular weight HA production by HA synthases, especially HAS-1, by interacting with TLR-4 receptors, displaces small fragments from TLR-4 receptors and at the same time blocks TLR-4 
activity [16] by preventing TLR-4 interaction with HA fragments derived from HA degradation while CD44 provides for their removal from the environment. At the same time, high molecular weight HA may also inhibit PKC, thereby limiting NF-kB activation [15] with the consequent contribution to inflammation resolution and tissue repair (panel D).

\section{Discussion}

The mechanisms that regulate the host response to non-infectious tissue injury are little understood, but increased ECM turnover is a hallmark of tissue injury. HA fragmentation during ECM degradation after acute tissue injury serves the important function of initiating the host innate immune response by providing an essential signal to macrophages and other cell types to produce chemokines that recruit other leukocyte subsets required to achieve tissue injury and to begin restoring tissue integrity [17, 20-22]. HA can be depolymerised into small fragments via oxygen radicals and enzymatic degradation by hyaluronidase, $\beta$-glucuronidase and hexosaminidase [23-24]. HA oligosaccharides may modulate immunocompetent cell types, such as dendritic cells and macrophages or in malignant cells through the TLR-4 receptor [2-3, 6, 11-12]. Recent data have demonstrated the involvement of low molecular weight HA and other GAGs in the modulation of inflammation by interacting with TLR-4 in mouse cartilage chondrocytes [16, 25]. Articular cartilage homeostasis is in fact a result of an intricate interplay between anabolic and catabolic, antiand pro-inflammatory, anti-and pro-apoptotic mediators [26], and chondrocytes are the versatile regulators of cartilage equilibrium.

The interaction of HA degradation products with CD44 also provides signals to initiate inflammation $[8,10,27]$. Other data support the hypothesis that a balance between low molecular weight HA and high molecular weight HA may control the activation of inflammation [28]. Therefore we suggest that high molecular weight HA was inactive on CD44 modulation, while the low molecular weight HA found at the inflammation site was active. This mechanism may be explained by the fact that, in the event of tissue destruction, high molecular weight HA is broken 
down into lower molecular weight HA species which have the ability to promote inflammation by inducing the release of reactive oxygen species such as NO, cytokines such as TNF- $\alpha$ and IL-1 $\beta$ and destructive enzymes such as MMPs and also by facilitating the recruitment of CD44 leukocytes [5, 29]. While high molecular weight HA maintains homeostasis and potentially downregulates inflammation, the generation of lower molecular weight HA may act as an endogenous danger signal leading to the activation of both innate and acquired immunity. This hypothesis, is supported by evidence that when clearance of lower molecular weight HA is lacking this leads to excess damage whereas the over-expression of high molecular weight HA is protective in the noninfectious lung injury model $[6,11]$.

The identification of the TLR-4 and CD44 receptors as the target for 6-mer HA had previously been demonstrated by several studies [2, 17-18, 30-33]. We recently reported that low molecular weight HA was able to stimulate inflammation in normal articular mouse chondrocytes [15-16]. In these studies it was shown that cytokines and other pro-inflammatory mediators were produced as the consequence of the interaction either between HA and TLR-4 or between HA and CD44 receptors. Although HA stimulation of TLR-4 and CD44 receptors activated two distinct pathways, in the end both converged in NF-kB activation [15-16]. However, in normal chondrocytes the effect exerted by low molecular HA was not found to be so high, although significant [15-16], compared with the effect obtained by other Authors in different cell types [2, 17, 32-34], and this was probably due to the different size of the HA fragment used. In addition, the studies using chondrocytes separately evaluated TLR-4 or CD44 receptor involvement [15-16] and there was no information available on the evaluation of both these receptors by HA fragment stimulation in chondrocytes. The aim of this study was therefore to evaluate at the same time both TLR-4 and CD44 involvement in human articular chondrocytes following stimulation with well-defined very small HA fragments which had been shown in previous results to have a great capacity to prime inflammation through these receptors. 
In this study, we examined the effects of 6-mer HA, at different concentrations, on both the TLR-4 and CD44 receptor modulation in human chondrocytes, compared with a series of cell groups blocked with the specific TLR-4 and CD44 receptors either separately or combined. This study suggests that 6-mer HA may interact with both receptors by stimulating a dose-dependent effect. In addition, the block of one captor at a time reduced the inflammatory effect exerted by 6-mer HA. The block of both receptors dramatically decreased the inflammatory effect, although a significantly low effect persisted. These results prompt the following considerations: on the one hand, the inflammatory effect exerted by 6-mer HA is the sum of the inflammatory effect individually stimulated by both receptors; on the other hand, both TLR-4 and CD44 receptors contributed equally to the production of the inflammatory cytokines. Furthermore, since the blocking of both receptors did not totally suppress inflammatory cytokine production, other different inflammatory pathways are presumed to be activated by small HA fragments. For instance, pathways not NF-kB dependent could be stimulate by TLR-4 or CD44 activation. In fact, the data obtained using the antibodies against NF-kB leads to the hypothesis that mediators comprises between CD44 activation and NF-kB could be responsible of pro-inflammatory cytokine level increment. The activation of NF-kB following CD44 stimulation is mediated by PKC. As PKC may, in part, directly activate TNF- $\alpha$ expression (35), it is plausible that the increment in the pro-inflammatory cytokine levels, in cells in which NF-kB activity was blocked, may be due to the activation of this pathway.

In conclusion, we believe that the HA pathways should be carefully considered for future antiinflammatory strategies although further studies are needed to fully confirm these hypotheses.

\section{Acknowledgements}

This study was supported by a PRA grant (Research Athenaeum Project 2008) from the University of Messina, Italy. 


\section{References}

[1] Beutler B, Jiang Z, Georgel P, Crozat K, Croker B, Rutschmann S, et al. Genetic analysis of host resistance: Toll-like receptor signalling and immunity at large. Annu Rev Immunol 2006; 24:353-89.

[2] Taylor KR, Trowbridge JM, Rudisill JA, Termeer CC, Simon JC, Gallo RL. Hyaluronan fragments stimulate endothelial recognition of injury though TLR4. J Biol Chem 2004; 279:17079-84.

[3] Jiang D, Liang J, Fan J, Yu S, Chen S, Luo Y, et al. Regulation of lung injury and repair by Toll-like receptors and hyaluronan. Nat Med 2005; 11:1173-79.

[4] Maquart FX, Bellon G, Pasco S, Monboisse JC. Matrikines in the regulation of extracellular matrix degradation. Biochimie 2005; 87:353-360.

[5] Adair-Kirk TL, Senior SM. Fragments of extracellular matrix as mediators of inflammation. Int J Biochem Cell Biol 2008; 40: 1101-10.

[6] Noble PW. Hyaluronan and its catabolic products in tissue injury and repair. Matrix Biol 2002; 21: 25-29.

[7] Aruffo A, Stamenkovic I, Melnick M, Underhill CB, Seed B. CD44 is the principal cell surface receptor for hyaluronate, Cell 1990; 61:1303-13.

[8] Heldin P, Karousou E, Bernert B, Porsch H, Nishitsuka K, Skandalis SS. Importance of hyaluronan-CD44 interactions in inflammation and tumorigenesis. Connect Tissue Res 2008; 49: $215-18$

[9] Loniewski KJ, Patial S, Parameswaran N. Sensitivity of TLR4- and -7-induced NF kappa B1 p105-TPL2-ERK pathway to TNF-receptor-associated-factor-6 revealed by RNAi in mouse macrophages. Mol Immunol 2007;44: 3715-23.

[10] Hutas G, Bajnok E, Gal I, Finnegan A, Glant TT, Mikecz K. CD44-specific antibody treatment and CD44 deficiency exert distinct effects on leukocytes recruitment in experimental arthritis. Blood 2008; 112: 4999-5006. 
[11] Jiang D, Liang J, Noble PW. Hyaluronan in tissue injury and repair. Annu Rev Cell Dev Biol 2007; 23: 435-61.

[12] Yamawaki H, Hirohata S, Miyoshi T, Takahashi K, Ogawa H, Shinohata R, et al. Hyaluronan receptors involved in cytokine induction in monocytes. Glycobiology 2009; 19:83-92.

[13] Fitzgerald KA, A.G. Bowie, B.S. Skeffington, L.A.J. O’Neill, Ras, protein Kinase Czeta and IkB kinase 1 and 2 are downstream effectors of CD44 during the activation of NF.kB by hyaluronic acid fragments in T-24 carcinoma cells, J. Immunol. 164 (2000) 2053-2063.

[14] Taylor KR, Yamasaki K, Radek KA, Di Nardo A, Goodarzi H, Golenbock D, et al. Recognition of hyaluronan released in sterile injury involves a unique receptor complex dependent on toll-like receptor 4, CD44, and MD-2. J Biol Chem 2007; 282:18265-75.

[15] Campo GM, Avenoso A, Campo S, D’Ascola A, Traina P, Calatroni A. Differential effect of molecular size HA in mouse chondrocytes stimulated with PMA. Biochim Biophys Acta 2009; 1790:1353-67.

[16] Campo GM, Avenoso A, Campo S, D’Ascola A, Nastasi G, Calatroni A. Molecular size hyaluronan differently modulates toll-like receptor-4 in LPS-induced inflammation in mouse chondrocytes. Biochimie 2010; 92:204-15

[17] Termeer CC, Hennies J, Voith U, Ahrens T, Weiss JM, Prehm P, et al. Oligosaccharides of hyaluronan are potent activators of dendritic cells. J Immunol 2000; 165:1863-70.

[18] Nishida Y, Knudson CB, Knudson W. Osteogenic protein-1 inhibits matrix depletion in a hyaluronan hexasaccharide-induced model of osteoarthritis. Osteoarthritis Cartilage 2004; $12: 374-82$

[19] Bradford MM. A rapid and sensitive method for the quantitation of microgram quantities of protein utilizing the principle of protein-dye binding. Anal Biochem 1976;72: 248-54.

[20] Noble PW. Hyaluronan and its catabolic products in tissue injury and repair. Matrix Biol $2002 ; 21: 25-29$.

[21] Stern R. Hyaluronan catabolism: a new metabolic pathway. Eur J Cell Biol 2004; 83:317-325. 
[22] Noble PW, Jiang D. Matrix regulation of lung injury, inflammation, and repair. Proc Am Thorac Soc 2006;3:401-404.

[23] Laurent TC, Fraser JR. Hyaluronan. Fed Am Soc Exp Biol J 1992; 6:2397-2404.

[24] Deguine V, Menasche M, Ferrari P, Fraisse L, Pouliquen Y, Robert L. Free radical depolymerization of hyaluronan by Maillard reaction products: role in liquefaction of aging vitreous. Int J Biol Macromol 1998; 22:17-22.

[25] Campo GM, Avenoso A, Campo S, Traina P, D’Ascola A, Calatroni A. Glycosaminoglycans reduced inflammatory response by modulatine toll-like receptor-4 in LPS-stimulated chondrocytes. Arch Biochem Biophys 2009;491:7-15.

[26] Schulze-Tanzil G. Activation and dedifferentiation of chondrocytes: implications in cartilage injury and repair. Ann Anat 2009;191:325-38.

[27] Weiss L, Slavin S, Reich S, Cohen P, Shuster S, Stern R, et al. Induction of resistance to diabetes in non-obese diabetic mice by targeting CD44 with a specific monoclonal antibody: Proc. Natl Acad Sci USA 2000; 97:285-90.

[28] Steeber DA, Venturi, Tedder TF. A new twist to the leukocyte adhesion cascade: intimate cooperation is key, Trends Immunol 2005; 26: 9-12.

[29] Eberlein M, Scheibner KA, Black KE, Collins SL, Chan-Li Y, Powell JD, et al. Anti-oxidant inhibition of hyaluronan fragment-induced inflammatory gene expression. J Inflamm 2008; 5:5-20.

[30] de la Motte CA, Hascall VC, Drazba J, Bandyopadhyay SK, Strong SA. Mononuclear leukocytes bind to specific hyaluronan structures on colon mucosal smooth muscle cells treated with polyinosinic acid:polycytidylic acid: inter-alpha-trypsin inhibitor is crucial to structure and function. Am J Pathol 2003; 163: 121-33.

[31] Knudson CB, Knudson W. Hyaluronan and CD44: modulators of chondrocyte metabolism. Clin Orthop Relat Res 2004; suppl 427:S152-62. 
[32] Fieber C, Baumann P, Vallon R, Termeer C, Simon JC, Hofmann M, et al. Hyaluronanoligosaccharide-induced transcription of metalloproteases. J Cell Sci 2004; 117: 359-67.

[33] Voelcker V, Gebhardt C, Averbeck M, Saalbach A, Wolf V, Weih F. Hyaluronan fragments induce cytokine and metalloprotease upregulation in human melanoma cells in part by signalling via TLR4. Exp Dermatol 2007;17:100-7

[34] Termeer C, Benedix F, Sleeman J, Fieber C, Voith U, Ahrens T, et al. Oligosaccharides of Hyaluronan activate dendritic cells via toll-like receptor 4. J Exp Med 2002;195: 99-111.

[35] Mitchell PG, Cheung HS. Protein kinase regulation of tumor necrosis factor alpha stimulated collagenase and stromelysin message levels in chondrocytes. Biochem Biophys Res Commun 1993; 196:1133-1141.

\section{Figure legends}

Fig.1

Effect of 6-mer HA oligosaccharide treatment at different concentrations and CD-44 and/or TLR-4 blocking antibodies (Ab) on chondrocyte TLR-4 mRNA expression (Panels A, B, C and D) and related protein production (Panels E, F, G and H). Values are the mean \pm S.D. of seven experiments and are expressed as the $n$-fold increase with respect to the Control (Panels A, B, C and D) and as both Densitometric analysis (Panels E, F, G and H) and Western Blot analysis (Panels I, L, M and N) for the TLR-4 protein levels. HA concentrations are expressed in $\mu \mathrm{g} / \mathrm{ml}$; ${ }^{*} \mathrm{p}<0.001$ vs CTRL.

Fig.2

Effect of 6-mer HA oligosaccharide treatment at different concentrations and CD-44 and/or TLR-4 blocking antibodies (Ab) on chondrocyte CD-44 mRNA expression (Panels A, B, C and D) and related protein production (Panels E, F, G and H). Values are the mean \pm S.D. of seven experiments and are expressed as the $n$-fold increase with respect to the Control (Panels A, B, C and D) and as 
both Densitometric analysis (Panels E, F, G and H) and Western Blot analysis (Panels I, L, M and

N) for the CD-44 protein levels. HA concentrations are expressed in $\mu \mathrm{g} / \mathrm{ml}$; ${ }^{*} \mathrm{p}<0.001$ vs CTRL.

Fig.3

Effect of 6-mer HA oligosaccharide treatment at different concentrations and CD-44 and/or TLR-4, or NF-kB blocking antibodies (Ab) on chondrocyte NF-kB p50/65 transcription factor DNA binding activity (Panels A, B, C and D). White bars represent the p/50 subunit, black bars represent the p/65 subunit. Values are the mean \pm S.D. of seven experiments and are expressed as Optical Density at $\lambda 450 \mathrm{~nm} / \mathrm{mg}$ protein of nuclear extract. HA concentrations are expressed in $\mu \mathrm{g} / \mathrm{ml}$; ${ }^{*} \mathrm{p}<0.05,{ }^{* *} \mathrm{p}<0.01,{ }^{* * *} \mathrm{p}<0.005$ and ${ }^{* * * *} \mathrm{p}<0.001$ vs CTRL; \#p<0.001 vs HA $10 \mu \mathrm{g} / \mathrm{ml}, 20 \mu \mathrm{g} / \mathrm{ml}$ and $40 \mu \mathrm{g} / \mathrm{ml}$, respectively for each corresponding dose group.

\section{Fig.4}

Effect of 6-mer HA oligosaccharide treatment at different concentrations and CD-44 and/or TLR-4, or NF-kB blocking antibodies (Ab) on chondrocyte TNF- $\alpha$ mRNA expression (Panels A, B, C and D) and related protein production (Panels E, F, G and H). Values are the mean \pm S.D. of seven experiments and are expressed as the $n$-fold increase with respect to the Control (Panels A, B, C and D) and as pg/ml for the TNF- $\alpha$ protein levels (Panels E, F, G and H). HA concentrations are expressed in $\mu \mathrm{g} / \mathrm{ml} ;{ }^{*} \mathrm{p}<0.05,{ }^{* *} \mathrm{p}<0.01,{ }^{* * *} \mathrm{p}<0.005$ and ${ }^{* * * *} \mathrm{p}<0.001$ vs CTRL; $\# \mathrm{p}<0.001$ vs HA $10 \mu \mathrm{g} / \mathrm{ml}, 20 \mu \mathrm{g} / \mathrm{ml}$ and $40 \mu \mathrm{g} / \mathrm{ml}$, respectively for each corresponding dose group.

\section{Fig.5}

Effect of 6-mer HA oligosaccharide treatment at different concentrations and CD-44 and/or TLR-4, or NF-kB blocking antibodies (Ab) on chondrocyte IL-6 mRNA expression (Panels A, B, C and D) and related protein production (Panels E, F, G and H). Values are the mean \pm S.D. of seven 
experiments and are expressed as the $n$-fold increase with respect to the Control (Panels A, B, C and D) and as pg/ml for the IL-6 protein levels (Panels E, F, G and H). HA concentrations are expressed in $\mu \mathrm{g} / \mathrm{ml} ;{ }^{*} \mathrm{p}<0.05,{ }^{* *} \mathrm{p}<0.01,{ }^{* * *} \mathrm{p}<0.005$ and $* * * * \mathrm{p}<0.001$ vs CTRL; $\# \mathrm{p}<0.001$ vs HA $10 \mu \mathrm{g} / \mathrm{ml}$, $20 \mu \mathrm{g} / \mathrm{ml}$ and $40 \mu \mathrm{g} / \mathrm{ml}$, respectively for each corresponding dose group.

\section{Fig.6}

Effect of 6-mer HA oligosaccharide treatment at different concentrations and CD-44 and/or TLR-4, or NF-kB blocking antibodies (Ab) on chondrocyte IL1- $\beta$ mRNA expression (Panels A, B, C and D) and related protein production (Panels E, F, G and H). Values are the mean \pm S.D. of seven experiments and are expressed as the $n$-fold increase with respect to the Control (Panels A, B, C and D) and as pg/ml for the IL1- $\beta$ protein levels (Panels E, F, G and H). HA concentrations are expressed in $\mu \mathrm{g} / \mathrm{ml} ;{ }^{*} \mathrm{p}<0.05,{ }^{* *} \mathrm{p}<0.01,{ }^{* * *} \mathrm{p}<0.005$ and ${ }^{* * * *} \mathrm{p}<0.001$ vs CTRL; $\# \mathrm{p}<0.001$ vs HA $10 \mu \mathrm{g} / \mathrm{ml}, 20 \mu \mathrm{g} / \mathrm{ml}$ and $40 \mu \mathrm{g} / \mathrm{ml}$, respectively for each corresponding dose group.

\section{Scheme. 1}

Overall scheme summarizing a hypothetical mechanism of HA-TLR-4 and HA-CD44 interaction on the basis of reported results. In normal conditions (panel A), native HA is produced on the inner surface of plasma membrane and extruded in the extracellular environment. It binds TLR-4 and CD44 receptors and maintains the homeostasis of the cell. CD44 deals with normal HA degradation and internalization and the successive passage to endosomes and to lysosomes where hyaluronidases handle its further degradation. Following inflammatory stimuli (panel B) by different agents, native HA is degraded into small fragments by reactive oxygen species and hydrolytic enzymes. In the acute phase of inflammation (panel C), HA fragments may prime inflammation via TLR-4 and CD44, by different pathways that finally both converge in NF-kB activation. NF-kB, in turn, translocates into the nucleus where it may prime the transcription of 
several inflammatory mediators. Inflammation mediators, in turn, are responsible for HA synthase induction, with a consequent increase in HA production that in part is deposited in tissues and in part degraded via the mechanism previously illustrated. The net result is the amplification and the perpetuation of inflammation. High molecular weight HA production by HA synthases (panel D) displaces small fragments from TLR-4 while CD44 handles their removal. At the same time high molecular weight HA may also inhibit PKC mediator. Therefore, in this way, the inflammatory pathway stimulated by TLR-4 receptor is inhibited by the masking of the receptors, the inflammatory pathway stimulated by CD44 is also inhibited by PKC inhibition and the consequence of this activity is the inflammation resolution and tissue repair. 
Figure $_{5}$
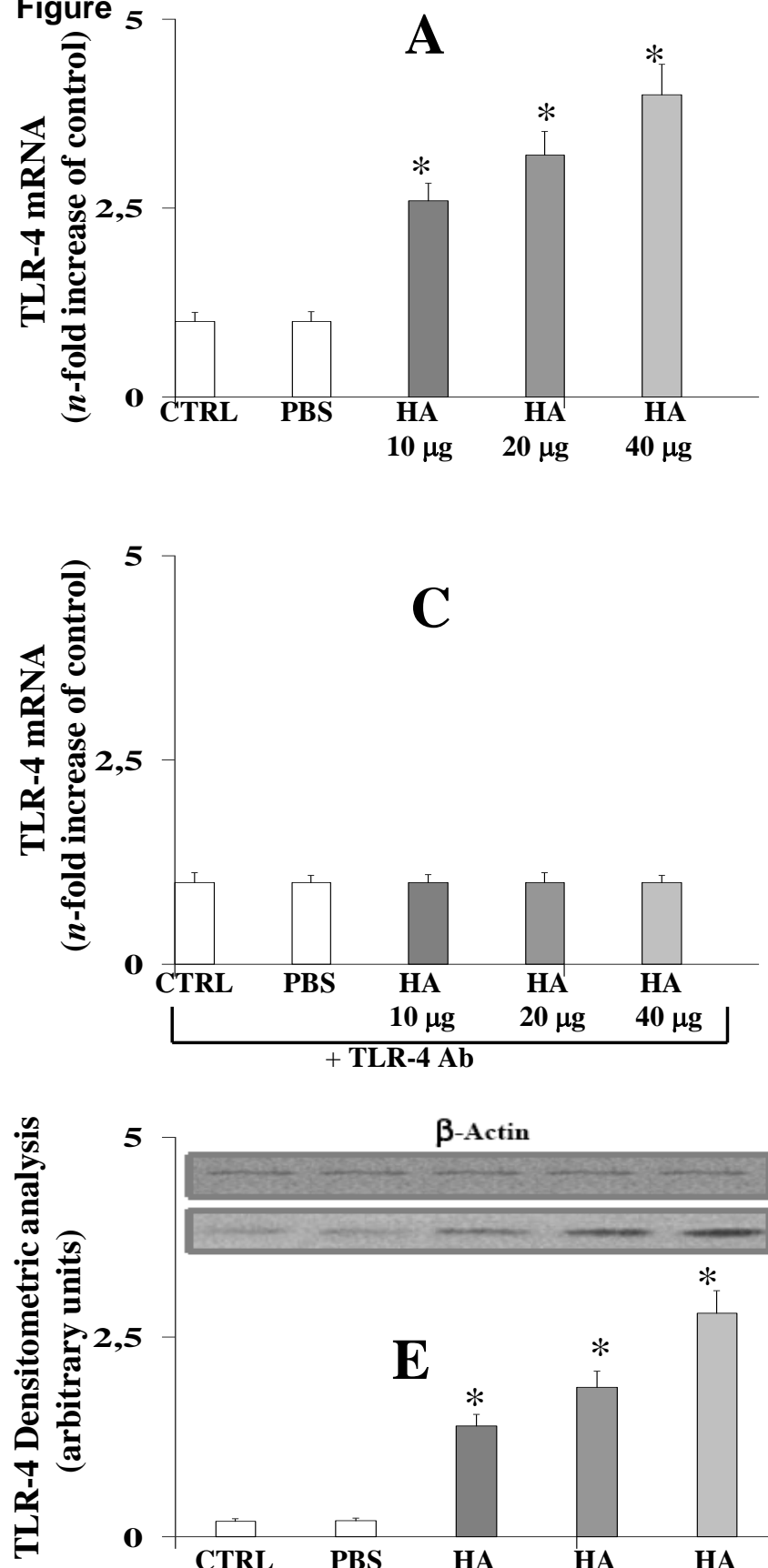
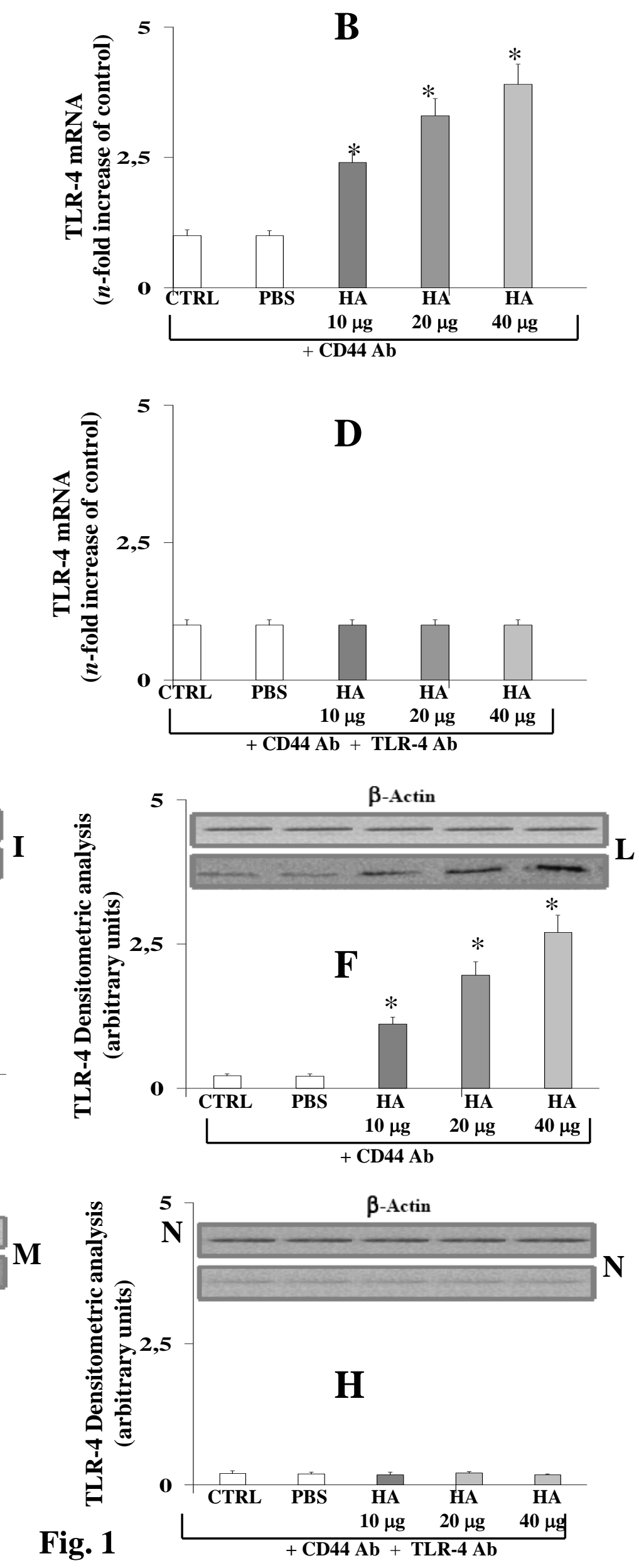

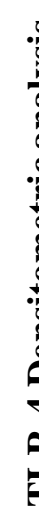

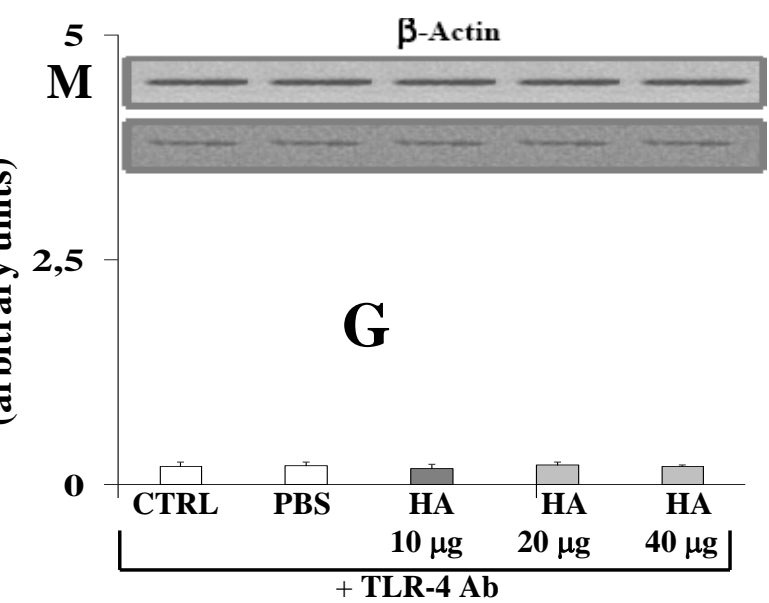



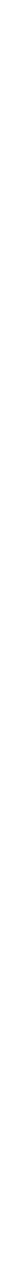

,
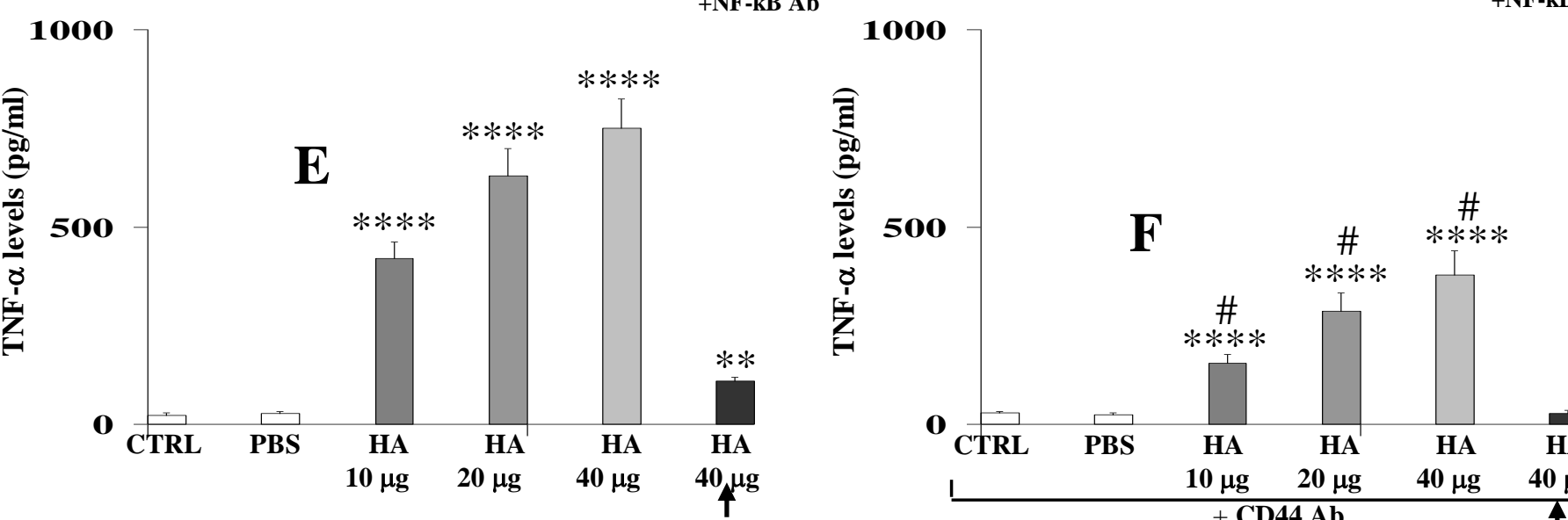

(
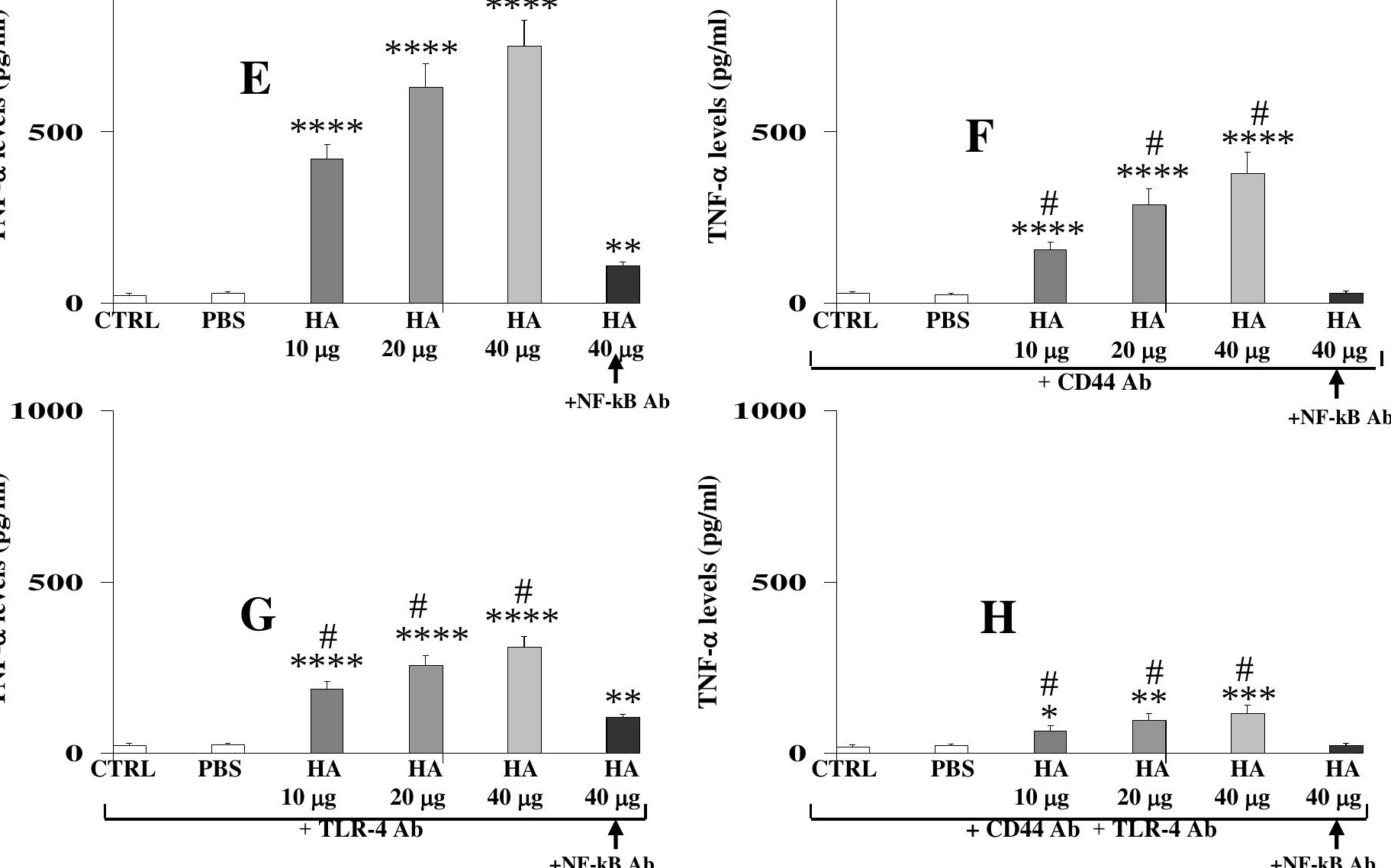

Fig. 4 

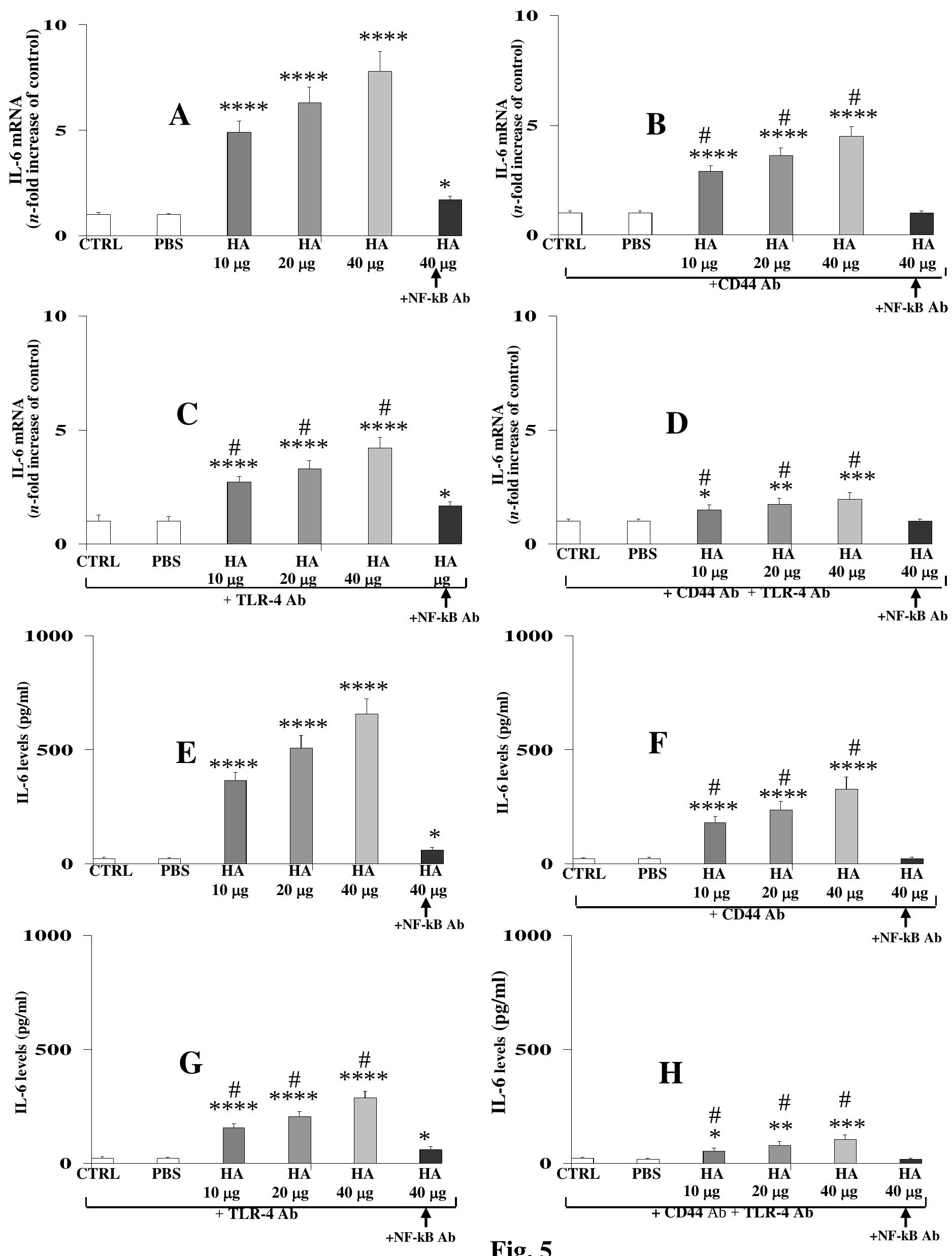

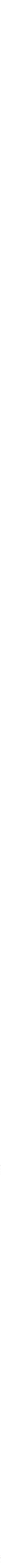

Fig. 6 

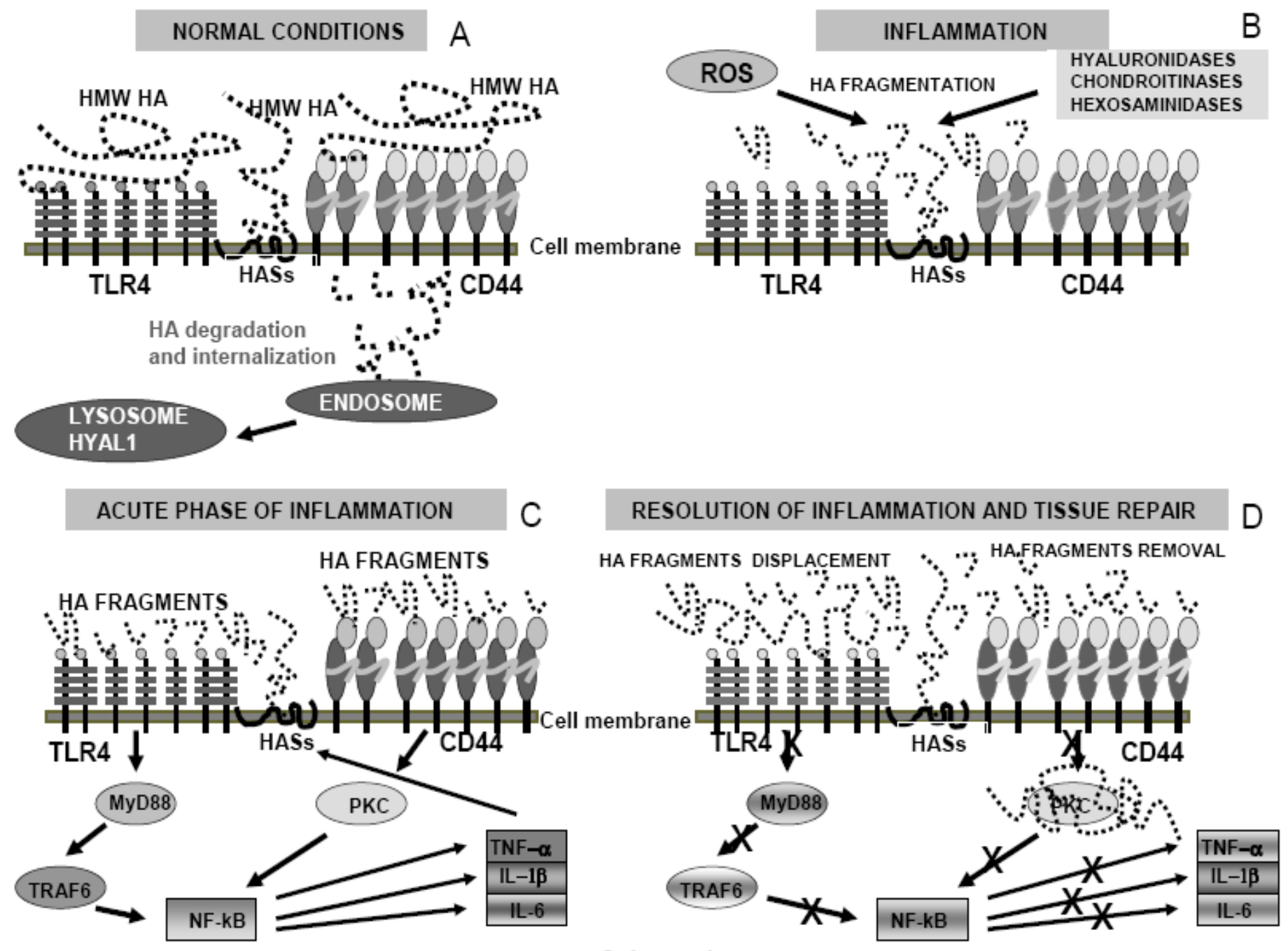

Scheme 1 
Small HA oligosaccharides primed inflammation in normal human chondrocytes by stimulating both TLR-4 and CD44 receptors. Blocking antibodies of these two receptors reduced NF-kB activation and inflammatory mediators.

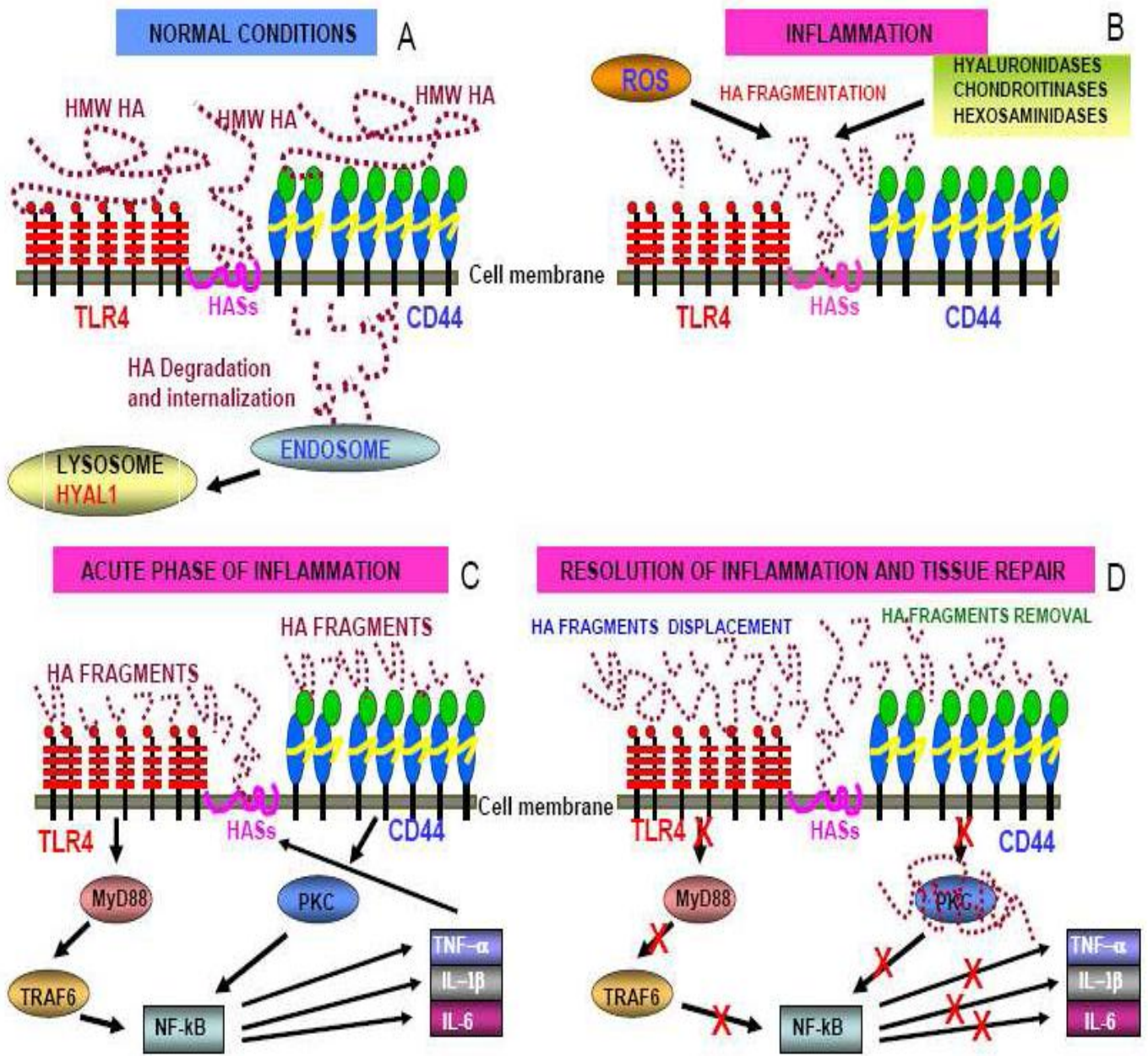

